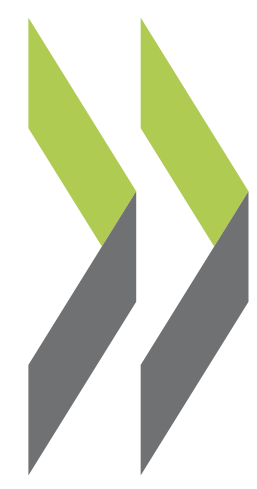

OECD Trade and Environment Working Papers 2011/05

\title{
The Trade Effects \\ of Phasing Out Fossil-Fuel Consumption Subsidies
}

\section{Jean-Marc Burniaux,}

Jean Château, Jehan Sauvage 


\section{OECD TRADE AND ENVIRONMENT WORKING PAPERS}

The OECD Working Paper series is designed to make available to a wide readership selected studies by OECD staff or by outside consultants.

This document has been declassified on the responsibility of the Joint Working Party on Trade and Environment under the OECD reference number COM/TAD/ENV/JWPTE(2010)52/FINAL.

Comments on the papers in this series are welcome and should be sent to env.contact@oecd.org or tad.contact@oecd.org.

\section{OECD TRADE AND ENVIRONMENT WORKING PAPERS}

are published on www.oecd.org/trade and www.oecd.org/environment

(C) OECD 2011

Applications for permission to reproduce or translate all or part of this material should be made to: OECD Publishing, rights@ oecd.org or by fax to +33145249930. 


\title{
Abstract \\ THE TRADE EFFECTS OF PHASING OUT FOSSIL-FUEL CONSUMPTION SUBSIDIES
}

\author{
by \\ Jean-Marc Burniaux, Jean Chateau and Jehan Sauvage
}

\begin{abstract}
Quoting a joint analysis undertaken by the OECD and the IEA, G-20 leaders committed in September 2009 to "rationalize and phase out over the medium term inefficient fossil-fuel subsidies that encourage wasteful consumption." This report draws on previous OECD work to assess the impact on international trade of phasing out fossilfuel consumption subsidies provided mainly by developing and emerging economies. The analysis employed the OECD's ENV-Linkages General-Equilibrium model and used the IEA's estimates of consumer subsidies, which measure the gap existing between the domestic prices of fossil fuels and an international reference benchmark. It shows that a co-ordinated multilateral removal of fossil-fuel consumption subsidies over the 20132020 period would increase global trade volumes by a very small amount $(0.1 \%)$ by 2020. While seemingly negligible, this increase hides the large disparities that are observed across countries (or regions) and products. Under the central scenario, which assumes a multilateral subsidy removal over the 2013-2020 period, trade in natural gas would be most affected, with a $6 \%$ decrease by 2020 . A reduction in the volume of both imports and exports from oil-exporting countries would be partly compensated by an expansion of trade flows (both imports and exports) involving OECD countries. This reallocation of trade flows would be most prevalent in products of energy-intensive industries. Looking beyond 2020, the contribution of oil-exporting countries to total world trade volumes would continue to be lower in 2050 than under the reference scenario.
\end{abstract}

JEL Classification: F17, F18, H23, O41, Q43, Q56.

Keywords: fossil-fuel subsidies, climate change, trade and environment, general equilibrium models, greenhouse-gas emissions.

\section{Acknowledgements}

This paper was written by Jean-Marc Burniaux, Jean Chateau and Jehan Sauvage of the OECD Environment Directorate (Burniaux and Chateau) and Trade and Agriculture Directorate (Sauvage), under the direction of Ronald Steenblik of the OECD Trade and Agriculture Directorate. The authors would like to express gratitude to Trevor Morgan from the International Energy Agency, who has worked extensively on some of the fossilfuel subsidy data used in this paper.

The authors are grateful to the delegates to the Joint Working Party on Trade and Environment for their comments and suggestions. The views expressed in the paper do not necessarily reflect the official views of the OECD nor of the governments of its member countries nor those of the European Union. 


\section{Table of contents}

Methodological approach......

\section{Tables}

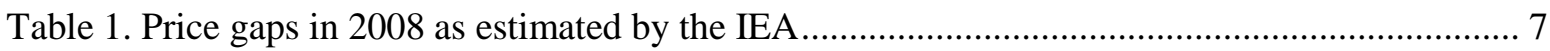

Table 2. Trade impacts of unilateral removal of fossil-fuel consumption subsidies ......................... 10

Table 3. Real exchange rates and terms-of-trade impacts of a multilateral removal of fossil-fuel subsidies.

\section{Figures}

Figure 1. Impact on world trade volumes in 2020 from a multilateral removal of fossilfuel subsidies, by major categories of goods and services.

Figure 2. Trade reallocation across regional trading area from a multilateral removal of fossil-fuel subsidies.

Figure 3. Trade reallocation across regional trading area from a multilateral removal of fossil-fuel subsidies.

Figure 4. Trade reallocation across regional trading area from a multilateral removal of fossil-fuel subsidies.

Figure 5. Central scenario: The impact on GHG emissions at the 2050 horizon

\section{Boxes}

The IEA method of quantifying price-gap estimates 


\section{THE TRADE EFFECTS OF PHASING OUT FOSSIL-FUEL CONSUMPTION SUBSIDIES}

\section{Introduction}

At the conclusion of their September 2009 Summit, G20 Leaders committed to "rationalize and phase out over the medium term inefficient fossil-fuel subsidies that encourage wasteful consumption". This decision came after a joint analysis made by the OECD and the IEA showing that removing fossil-fuel consumption subsidies in a number of non-OECD countries could reduce world greenhouse-gas (GHG) emissions by $10 \%$ in 2050 compared with their level in the absence of such a reform (OECD, 2009). Indeed, these subsidies are huge. According to the most recent IEA estimates, total fossil-fuel consumer subsidies amounted to USD 557 billion in 2008 - almost six times the yearly aid flows to developing countries via Official Development Assistance (ODA) - and USD 312 billion in 2009 (IEA, 2010). Fossil-fuel consumer subsidies ${ }^{1}$ are quite substantial in some countries, especially in several oil-exporting countries, where they amount to $10 \%$ or more of GDP. Even in oil-importing countries like India, subsidies as a share of GDP are not negligible, amounting to almost 5\% of its GDP in 2008, and $2.5 \%$ of its GDP in 2009.

Previous OECD analysis (Burniaux et al., 1992, 2009; OECD, 2009; Burniaux and Chateau, 2011; IEA et al., 2010) has quantified the economic and environmental impacts of subsidies to fossil-fuel consumption using a dynamic computable general-equilibrium (CGE) model. The results have generally indicated that phasing-out fossil-fuel consumer subsidies could lead to a $10 \%$ reduction in global greenhouse-gas emissions in 2050 compared with a business-as-usual scenario. Moreover, if countries that subsidise the consumption of fossil fuels removed these subsidies unilaterally, most would realise real income gains. These gains would arise from a more efficient allocation of resources across sectors. A different outcome would occur, however, if all countries that subsidise fossil-fuel consumption were to remove these subsidies multilaterally. In that event, the terms-of-trade changes associated with a decrease in world energy prices due to reduced demand should lead to a different distribution across countries of real income gains and losses.

In this modelling approach, subsidies were specified using a synthetic indicator usually referred to as "price gaps" (see below). Past analyses focused on simulating the impact of a removal of these price gaps on macroeconomic variables, such as changes in GDP or in aggregate household real income (as measured by the Hicksian equivalent variation in income relative to the baseline scenario). However, these analyses largely ignored the impact on the volumes and directions of international trade flows, although the CGE models on which these analyses were based provide such kind of information.

1. This analysis covers subsidies benefitting consumers of coal, refined petroleum products, natural gas, and electricity. The electricity subsidy may in principle cover subsidies to nuclear-based, hydroelectric and renewable electricity sources, hence including subsidies that do not increase the consumption of fossil fuels. However, these subsidies are negligible in the countries covered by the IEA database. 
This paper aims at filling this gap. It concentrates on the international trade impacts of the removal of fossil-fuel subsidies, including the balance between aggregate changes in total trade volumes and the reallocation of trade across sectors and trading areas. Its focus is mainly on the medium-term impacts of subsidy reform, i.e. measuring the impacts on trade in 2020 in a scenario in which subsidies are gradually removed from 2013 to 2020, although one section briefly analyses some major long-term implications at the 2050 horizon.

The remainder of this paper proceeds as follows. Section 2 discusses the nature of fossil-fuel consumer subsidies, their scope, the existing data collected by the IEA and the method used to assess these subsidies. Section 3 discusses the main results from different scenarios of subsidy removal. It starts with a short subsection that addresses a scenario of unilateral removals in order to explain the various price and volume mechanisms that drive the adjustment of the current account. This is followed by an analysis of the centralcase scenario, which simulates a multilateral reform of fossil-fuel subsidies in all nonOECD countries simultaneously. This analysis focuses on trade reallocation across major categories of goods and services and major trading areas. Section 4 concludes.

\section{Methodological approach}

Governments support the consumption and production of fossil fuels in numerous ways: by intervening in markets in such a way as to affect costs or prices, by transferring funds to recipients directly, by assuming part of their risk, by selectively reducing the taxes they would otherwise have to pay, and by undercharging for the use of governmentsupplied goods or assets. Often, more than one transfer mechanism is used. For example, on the consumption side, a government may provide tax breaks to purchasers of motor vehicles and at the same time regulate the price of transport fuels below the international market price or even below the cost of producing the fuels. The effects of subsidies depend not only on how governments subsidise but also on what economic variables they subsidise - i.e. consumer or producer prices, consumption or production levels, enterprise revenues, intermediate inputs, or production factors (IEA, OPEC, OECD, World Bank, 2010).

While each form of consumer subsidy should ideally be modelled explicitly in order to quantify their impact, this approach was not feasible in this analysis due to lack of data. Instead, the approach followed here is a simplified one usually referred to as the "pricegap approach". Therefore, this analysis only concerns those types of consumer subsidies that are mostly present in non-OECD countries: ${ }^{2}$ those that depress the domestic market price of a fuel or electricity below a reference price. Support to fossil-fuel producers, as well as forms of support to consumption that cannot be observed through price gaps, would also be worth examining, but estimates of such support is only now beginning to be compiled in a systematic way.

\section{The IEA's price-gap approach}

Most of the data on energy-consumer subsidies that have been published for nonOECD countries in recent years relate to petroleum products, natural gas and coal (IEA, 2006 and 2008) or to petroleum products only (Coady et al., 2010), and rely on the

2. Although the IEA database on fossil-fuel subsidies includes two OECD countries among a sample of 37 countries, the rest of this paper refers to subsidies in non-OECD countries for the sake of simplicity. 
measurement of price gaps. The transfers measured with this approach comprise subsidies to fossil fuels used in final and intermediary consumption (including subsidies to fossilfuel inputs to electric power generation).

The "price-gap" method is described in Box $1 .^{3}$ It aims at summarising various forms of consumer-price interventions using one single indicator: the observed price deviation between the domestic consumer price and a reference price considered as undistorted (usually the corresponding international price). Although it is by far the most common approach used in the literature to evaluate transfers supporting consumption through price instruments, some authors have pointed out a number of weaknesses when this approach is applied to energy goods (Koplow, 2009). ${ }^{4}$

\section{Box 1. The IEA method of quantifying price-gap estimates}

Energy subsidies are estimated using a price-gap approach, which compares end-user consumer prices with reference prices corresponding to the full cost of supply or, where available, the international market price, adjusted for the costs of transportation and distribution. This approach captures all subsidies that reduce consumer prices below those that would prevail in a competitive market. Such subsidies can take the form of direct financial interventions by government, such as grants, tax rebates or deductions and soft loans, and indirect interventions, such as price ceilings and free provision of energy infrastructure and services.

Simple as the approach may be conceptually, calculating the size of subsidies in practice requires a considerable effort in compiling price data for different fuels and consumer categories and computing reference prices. For traded forms of energy, such as refined petroleum products, the reference price corresponds to the export or import border price (depending on whether the country is an exporter or importer) plus internal distribution margins. For non-traded energy, such as electricity, the reference price is the estimated long-run marginal cost of supply. VAT is added to the reference price where the tax is levied on final energy sales). Other taxes, including excise duties, are not included in the reference price. So, even if the pre-tax pump price of gasoline in a given country is set by the government below the reference level, there would be no net subsidy if an excise duty large enough to make up the difference is levied. The aggregated results are based on net subsidies only for each country, fuel and sector. Negative subsidies, i.e. where the final price exceeds the reference price, were not taken into account. In practice, part of the subsidy in one sector or for one fuel might be offset by net taxes in another. Subsidies were calculated only for end-user consumption, to avoid the risk of double counting: any subsidies on fuels used in power generation would normally be reflected at least partly in the final price of electricity. All the calculations for each country were carried out using local prices, and the results were converted to US dollars at market exchange rates.

Source: based on IEA (2006).

This analysis covers 37 countries, including two OECD countries (South Korea and Mexico), and reflects the average situation in $2008 .{ }^{5}$ The IEA estimates that, altogether, these countries account for roughly $95 \%$ of global subsidised fossil-fuel consumption measurable through price gaps. The price wedges estimated for 2008 by energy source and by country or region are significant in a number of cases (Table 1). The first column of the Table shows the average wedges for all demands that are effectively subsidised in

3. IEA (1999) provides a more detailed discussion of the price-gap approach and practical issues relating to its use in calculating subsidies and their effects.

4. For instance, the identification of an appropriate reference price is not always obvious for non-traded goods such as electricity; international energy prices could in turn be distorted during some periods; and, finally, the price-gap estimates do not capture all subsidies. Regarding this last point, OECD (2003) suggested that the price-gap method tends to underestimate the level of subsidies in countries that use this kind of market-distorting instrument.

5. Data for 2009 were released by the IEA in early November 2010, but these were made available too late to incorporate them into the current analysis. 
each country or region, thereby illustrating the magnitude of the wedges. The second column reports the average wedge across all demands (including demands that are not subsidised), so that the difference between both columns reflects the coverage of the subsidies across demands. Countries not covered in the IEA database are included in regional aggregates (for instance, the Rest of the World region) by assuming zero wedges.

Table 1. Price gaps in 2008 as estimated by the IEA

\begin{tabular}{|c|c|c|c|}
\hline \multirow[b]{2}{*}{ Country } & \multirow[b]{2}{*}{ Energy } & \multicolumn{2}{|c|}{$\%$ Deviation of domestic relative to world prices } \\
\hline & & $\begin{array}{l}\text { Average subsidy rate over the } \\
\text { demand categories that are } \\
\text { effectively subsidised for } \\
\text { each type of fuel }\end{array}$ & $\begin{array}{c}\text { Average subsidy rate over the } \\
\text { total consumption of } \\
\text { each type of fuel }\end{array}$ \\
\hline \multirow[t]{4}{*}{ China } & Coal & -6.6 & -1.2 \\
\hline & Gas & -21.4 & -7.1 \\
\hline & Refined oil & -19.7 & -1.7 \\
\hline & Electricity & -12.8 & -1.7 \\
\hline \multirow[t]{4}{*}{ India } & Coal & 0.0 & 0.0 \\
\hline & Gas & -60.4 & -32.2 \\
\hline & Refined oil & -41.8 & -20.4 \\
\hline & Electricity & -20.3 & -1.7 \\
\hline \multirow[t]{4}{*}{ Brazil } & Coal & 0.0 & 0.0 \\
\hline & Gas & 0.0 & 0.0 \\
\hline & Refined oil & 0.0 & 0.0 \\
\hline & Electricity & 0.0 & 0.0 \\
\hline \multirow[t]{4}{*}{ Russia } & Coal & 0.0 & 0.0 \\
\hline & Gas & -78.8 & -21.4 \\
\hline & Refined oil & 0.0 & 0.0 \\
\hline & Electricity & -37.6 & -24.8 \\
\hline \multirow[t]{4}{*}{ Oil-exporting countries ${ }^{2}$} & Coal & 0.0 & 0.0 \\
\hline & Gas & -37.7 & -11.4 \\
\hline & Refined oil & -45.5 & -34.3 \\
\hline & Electricity & -47.2 & -43.5 \\
\hline \multirow{4}{*}{$\begin{array}{l}\text { Non-EU Eastern } \\
\text { European countries }^{2}\end{array}$} & Coal & 0.0 & 0.0 \\
\hline & Gas & -30.3 & -15.8 \\
\hline & Refined oil & -5.7 & -0.6 \\
\hline & Electricity & -19.4 & -10.9 \\
\hline \multirow[t]{4}{*}{ Rest of the world } & Coal & -7.4 & -0.9 \\
\hline & Gas & -29.5 & -8.2 \\
\hline & Refined oil & -5.7 & -4.1 \\
\hline & Electricity & -9.1 & -5.8 \\
\hline
\end{tabular}

1. Energy subsidies are approximated by the difference between the domestic energy price and a world reference price.

2. See Table A2 in Annex I for the details about these regions.

Source: Authors' calculations based on IEA data on fossil-fuel consumption subsidies prepared for the G-20. 
The energy wedges differ across energy sources and countries (or regions). Energy tends to be subsidised more heavily in Russia (especially for natural gas), India and the oil-exporting countries. ${ }^{6}$ By contrast, the subsidy rates estimated by the IEA for China are more moderate. These lower subsidy rates in China are partly the consequence of a reform undertaken in 2008.

\section{Assumptions and scenarios}

The impact of subsidy reform is estimated using the ENV-Linkages model developed by the Environment Directorate of the OECD. This model is a global CGE model, disaggregated by sectors and countries or regions, and running up to the year 2050 using recursive dynamics (see Burniaux and Chateau [2010] for a more detailed description of the modelling structure). All scenarios in this paper are shown relative to a baseline projection simulating the evolution of the world economy up to 2050 under the assumption of no climate-change policies beyond those that are already in place. This projection is based on an underlying long-term economic growth scenario described in Duval and de la Maisonneuve (2010). The price gaps estimated by the IEA for 2008 are introduced by calibration in the initial year of the model, 2005, and they are assumed to remain constant in percentage terms up to 2050. In simulations of generic subsidy reforms, these price gaps are gradually phased-out over the period 2013 to 2020.

The ENV-Linkages model relies on a number of assumptions that may have a bearing on estimates of the trade effects of phasing out fossil-fuel subsidies. Among these assumptions is the fact that international capital flows are exogenous. As explained in Burniaux and Chateau (2010), this means that any new current imbalance is to be immediately compensated by a corresponding change in the real exchange rate. The baseline assumes that the size of each current-account surplus (deficit) is fixed and that capital outflows (inflows) adjust accordingly. It follows that international capital flows are exogenously determined by the calibrated levels of initial current-account balances. Any new current imbalance triggered by a policy change (such as a removal of fossil-fuel subsidies) would thus immediately translate into a correcting adjustment in the countries' real exchange rates.

The assumption of exogenous international capital flows is meant to distinguish shortrun current imbalances that are compensated through real exchange-rate changes from the long-run ones that remain. Modelling international capital flows remains, however, problematic since there is no consensus as to what empirically determines the various types of flows across countries. One solution could be to adopt a recursive framework as in the GTAP-Dyn model but this ad-hoc specification is quite complex and results in international capital flows being far too volatile (Ianchovichina and McDougall, 2000). Another could be to assume forward-looking agents as in the G-Cubed model where international capital flows stem from intertemporal optimisation (McKibbin and Wilcoxen, 1999). However, this would represent a significant departure from the current version of the ENV-Linkages model and might result in less disaggregation than is now available.

Another source of uncertainty is related to the assumed values for the price-elasticity of fossil-fuel supply. The central scenario outlined below is based on the assumption that the supply of coal is much more elastic (with an elasticity equal to 10) than that for crude

6. Although, in the latter case, this partly reflects the use of the international prices for refined oil products as reference prices. 
oil and natural gas (with elasticities respectively equal to 1.0 and 0.8 ). As illustrated in Burniaux and Chateau (2011), lower supply elasticities yield lower emission reductions because a large proportion of the reductions achieved in non-OECD countries are offset by emission increases in OECD countries. In the extreme case of a completely inelastic supply of fossil fuels, the environmental benefits of a subsidy removal become negligible. Real-income losses become lower too as fewer resources are left in the ground. The economic and environmental impacts of reforming fossil-fuel subsidies are also likely to be affected by the magnitude of energy-demand reactions to changes in fossil-fuel prices. Further work would here be needed to assess the extent to which outcomes are sensitive to household preferences and technology specifications.

The following analysis first considers illustrative scenarios in which countries that subsidise their consumption of fossil fuels remove subsidies unilaterally. The purpose of this experiment is to illustrate the major mechanisms of trade adjustment. However, subsidy reform is more likely to occur through a succession of multilateral co-operative rounds in which all countries that subsidise fossil-fuel consumption remove subsidies simultaneously and gradually. In addition, in order to be as realistic as possible, the impact of this multilateral reform has to be simulated in a context that is consistent with the decision taken after $15^{\text {th }}$ Conference of the Parties (COP15) to the United Nations Framework Convention on Climate Change in Copenhagen, wherein 75 countries, including all OECD countries, committed to restrict their emissions below declared targets in 2020. Thus, the central policy scenario considered in this paper assumes that all of the 37 countries covered by the IEA (2010) fossil-fuel subsidies database remove their subsidies gradually from 2013 to 2020 . In the absence of any further assumption, emissions in countries that do not remove fossil-fuel subsidies (OECD countries and Brazil) would increase due to the existence of carbon leakages ${ }^{7}$ (Burniaux and Chateau, 2011), unless this increase is prevented by the existence of the above-mentioned targets. Therefore, in the central policy scenario of multilateral subsidy reform, emissions in OECD countries and Brazil are assumed to remain capped to prevent emissions in these countries from exceeding a given level (as would be the case if emissions in these countries were bound to their declared targets).

\section{Main results}

\section{Scenarios of unilateral removal}

If each non-OECD country were to remove its fossil-fuel subsidies unilaterally, it would generally record welfare gains, in line with what is suggested by theory. Most countries or regions report welfare gains ranging from $0.3 \%$ in the rest-of-the-world regional aggregate to more than $4 \%$ in the oil-exporting countries in 2050 . These gains correspond to the welfare improvement associated with the subsidy removal together with, in most cases, a more efficient allocation of resources across sectors (Burniaux and Chateau, 2011).

Trade adjustments in countries that remove their subsidies are driven by the assumption that international capital flows in a given year are exogenous and always equal to their baseline levels' In other words, the model depicts an equilibrium situation in

7. Because the consumption of fossil fuels in reforming countries is reduced due to the subsidy removal, international fossil-fuel prices fall, thereby inducing an increase in fossil-fuel consumption in countries that do not remove any such subsidies. 
which any transitory trade imbalances have been compensated through the adjustment of the real exchange rates such as to restore the same current-account levels as in the baseline projection.

In energy-importing countries (e.g. India), the removal of fossil-fuel subsidies drastically reduces imports of fossil fuels (Table 2). This generates a transitory current account surplus that is absorbed by an appreciation of the real exchange rates and of the country's terms-of-trade. In turn, this appreciation results in an increase in non-energy imports and a decline in exports. In fossil-fuel exporting countries, the main effect is a drop of competitiveness of the exports of energy-intensive industries (EIIs) as a result of the subsidy removal. This induces a transitory current account deficit that is equilibrated partly through the terms-of-trade appreciation resulting from the increase of EIIs export prices and through a depreciation of the real exchange rate. Table 2 confirms that the unilateral removal of domestic subsidies to fossil-fuel consumption would reduce the competitiveness of exports from countries that undertake this policy, either directly through the adverse effect on the export price of EIIs (such as in fossil-fuel exporting countries) or indirectly through a real exchange rate appreciation (such as in fossil-fuel importing countries).

Table 2. Trade impacts of unilateral removal of fossil-fuel consumption subsidies

(\% deviation relative to the baseline in 2020 )

\begin{tabular}{lcccc}
\hline \multicolumn{1}{c}{ Country or region } & $\begin{array}{c}\text { Real } \\
\text { exchange rate }\end{array}$ & $\begin{array}{c}\text { Terms } \\
\text { of trade }\end{array}$ & $\begin{array}{c}\text { Exports } \\
\text { (volume) }\end{array}$ & $\begin{array}{c}\text { Imports } \\
\text { (volume) }\end{array}$ \\
\hline China & $0.5 \%$ & $0.1 \%$ & $-0.1 \%$ & $0.1 \%$ \\
India & $3.2 \%$ & $2.2 \%$ & $-5.8 \%$ & $0.5 \%$ \\
Russia & $-2.6 \%$ & $1.5 \%$ & $-1.6 \%$ & $-0.2 \%$ \\
Oil-exporting countries & $-1.4 \%$ & $2.1 \%$ & $-1.4 \%$ & $0.3 \%$ \\
Non-EU eastern European countries & $-0.4 \%$ & $0.3 \%$ & $-0.5 \%$ & $-0.2 \%$ \\
Rest of the world & $0.3 \%$ & $0.1 \%$ & $-0.3 \%$ & $0.0 \%$ \\
\hline
\end{tabular}

Source: OECD ENV Linkages Model based on fossil-fuel subsidies data estimated by the IEA.

\section{Scenario of multilateral subsidy removal}

A different outcome would prevail under the central scenario, which combines a simultaneous multilateral removal of fossil-fuel subsidies in all countries with a cap on emissions in the remaining countries (OECD countries and Brazil). Under this scenario, world GHG emissions would be reduced by $3 \%$ in 2020 and $10 \%$ in 2050 relative to the baseline projection (IEA, OPEC, OECD, World Bank, 2010; Burniaux and Chateau, 2011). Global real income would increase slightly but these gains would be unevenly distributed across countries and regions. India would benefit from an increase in welfare of $3 \%$ in 2050 relative to the baseline. However, some of the non-OECD countries that remove their subsidies, including Russia and the oil-exporting countries, would no longer enjoy the welfare gains they faced in scenarios in which they act alone. This is because the efficiency gains from improved resource allocation would be more than offset by the terms-of-trade losses associated with the fall in world energy prices and consumption that a multilateral removal of subsidies would induce. The resulting income losses for energyexporting countries would be, however, compensated by a longer production profile over time as a result of slower depletion. By contrast, fossil-fuel importing OECD countries 
would record real income gains associated with an improvement in their terms-of-trade due to falling world energy prices (Table 3).

Table 3 confirms the decrease in the terms-of-trade that would be experienced by oilexporting countries in 2020 following a fall in international energy prices, ranging from $1.2 \%$ for coal to $6.7 \%$ and $6.4 \%$ for crude oil and natural gas respectively. ${ }^{8}$ By contrast, real exchange rates and terms of trade appreciate in fossil-fuel importing non-OECD countries that remove their subsidies (in particular, India) and in fossil-fuel importing OECD countries (such as in Japan).

Table 3. Real exchange rates and terms-of-trade impacts of a multilateral removal of fossil-fuel subsidies (\% deviation relative to the baseline in 2020)

\begin{tabular}{lcc}
\hline \multicolumn{1}{c}{ Country or world region } & Real exchange rate $^{1}$ & ${\text { Terms of } \text { trade }^{2}}^{\mathbf{2}}$ \\
\hline Australia and New Zealand & -0.3 & -0.6 \\
Japan & 0.5 & 2.7 \\
Canada & -0.5 & -1.1 \\
United States & 0.2 & 0.8 \\
European Union and EFTA & 0.1 & 0.2 \\
Brazil & 0.2 & 0.3 \\
China & 0.8 & 0.2 \\
India & 4.0 & 3.9 \\
Russia & -4.0 & -1.7 \\
Oil-exporting countries & -2.0 & -3.9 \\
Rest of the world & 0.6 & 0.1 \\
Non-EU eastern European countries & -2.4 & -2.8 \\
\hline
\end{tabular}

1. Real exchange rates are defined as the change in Consumer Price Index of the region vis-à-vis United States, where all countries use the same basket of goods as weights, the US consumer budget shares.

2. Terms of trade for each country are defined as the ratio of the real price index of exports (FOB prices) to the real price index of imports (CIF prices).

Source: OECD ENV-Linkages Model based on fossil-fuel subsidies data estimated by the International Energy Agency (IEA).

Figure 1 reports the changes in total world trade volumes for services, industrial and agricultural products, and energy commodities. Trade in fossil fuels responds differently to subsidy removal. World trade volumes for coal are reduced slightly (by $1 \%$ ), reflecting the limited impact of reforms on the international price of coal. Trade in natural gas shrinks by $6 \%$ in 2020 , mainly due to a fall by more than a third in natural gas trade among oil-exporting countries. Despite lower international gas prices, trade reallocation is hindered by the fact that most international trade in natural gas takes place between countries within the same region. ${ }^{9}$ By contrast, there is no reduction in world trade volumes for refined oil products and a slight increase $(0.7 \%)$ for crude oil. This increase corresponds to a fall in international oil prices, together with a reallocation of crude-oil production in oil-exporting countries towards exports to OECD countries that increase by almost $8 \%$ compared with the baseline levels.

8 . The magnitudes of these energy-price falls reflect the assumption that the world supply of coal is more elastic than for crude oil and natural gas.

9. In the baseline projection, $50 \%$ of the total trade in natural gas takes place among OECD countries and another $20 \%$, among oil exporting countries. 
Overall, world trade volumes increase slightly (by $0.1 \%$ ), which mainly reflects the expansion of trade volumes in the products of energy-intensive industries (by almost 1\% relative to the baseline). As discussed below, this increase corresponds to the competitiveness gains recorded by these industries in OECD countries, despite the existence of a cap on their GHG emissions.

Figure 1. Impact on world trade volumes in 2020 from a multilateral removal of fossil-fuel subsidies, by major categories of goods and services

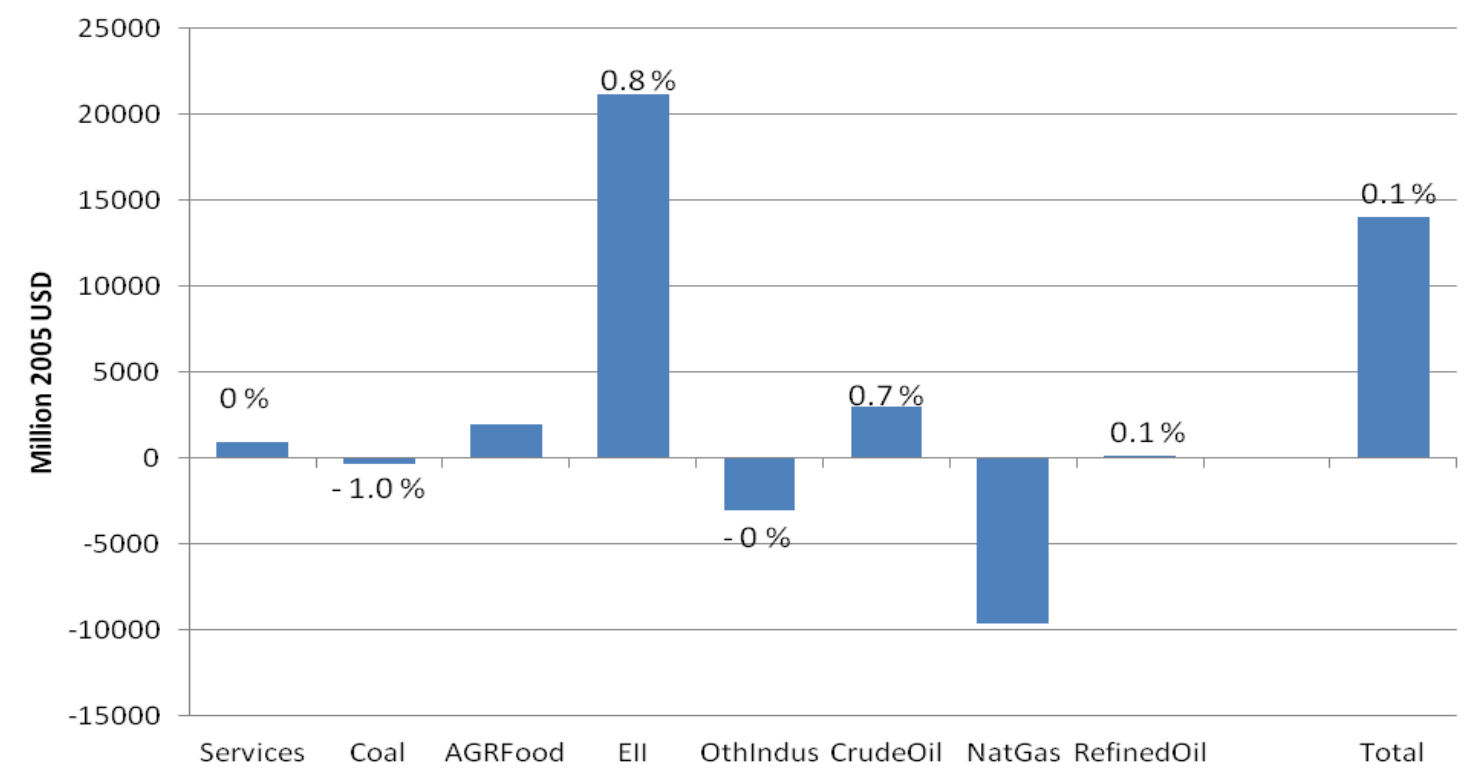

Percentages correspond to deviations relative to the baseline in 2020.

Source: OECD ENV-Linkages Model based on fossil-fuel subsidies data estimated by the IEA.

Figure 2 reports the bilateral changes in trade reallocation across the main trading areas that result from the removal of subsidies. These changes are estimated in 2020 and expressed in volume levels relative to the baseline. The four bars on the left report an increase in total export volumes from OECD countries by a little more than USD 30 billion, ${ }^{10}$ mainly as a result of an increase in both intra-OECD trade and exports to nonoil-exporting, non-OECD countries. Meanwhile, total OECD imports in volume also increase by around USD 30 billion (right-hand bars), which includes USD 14 billion in additional imports from oil-exporting countries that mainly consist of cheaper oil products. Total trade volumes increase in 2020 by almost USD 15 billion, as in Figure 1. This results from a combination of expanding OECD trade (both imports and exports) and a shrinking contribution (of both imports and exports) of trade by oil-exporting countries. Trade adjustments in the remaining non-OECD countries are driven by a real exchangerate appreciation that results from the removal of fossil-fuel subsidies and the resulting drop in exports (mainly services and other industries), along with an increase in imports of mainly energy-intensive goods from OECD countries (Figure 2).

10. All dollar amounts are expressed in 2005 United States dollars. 
Figure 2. Trade reallocation across regional trading area from a multilateral removal of fossil-fuel subsidies (Changes in volumes in 2020 relative to the baseline)

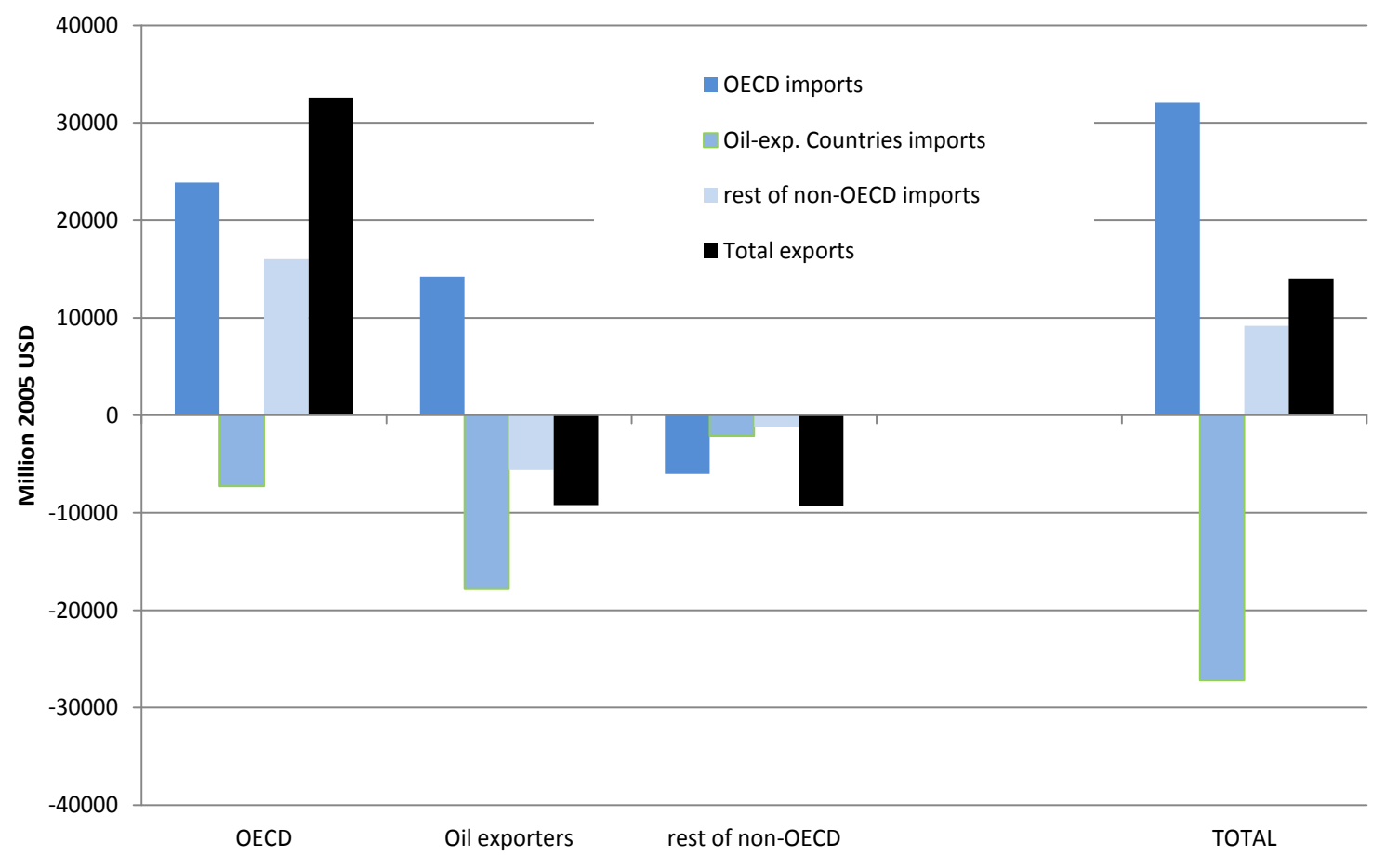

Bars correspond to bilateral trade flows. For instance, the three left-hand bars show the changes in level relative to the baseline of OECD exports to OECD countries (+24 billion USD 2005), to oil-exporting countries (-7 billion USD 2005) and to remaining non-OECD countries (+16 billion USD 2005). Total OECD exports - the fourth lefthand bar - increase by 33 billion USD 2005. In the meantime, total OECD imports - the first right-hand bar increase by 32 billion USD 2005.

Source: OECD ENV-Linkages Model based on fossil-fuel subsidies data estimated by the IEA.

Figure 3 reports these changes expressed in terms of the percentage deviations relative to the baseline. The major change relative to the business-as-usual baseline is the lower contribution to world trade of oil-exporting countries since their total imports decrease by more than $2 \%$ in 2020. Trade between oil-exporting countries falls by almost $12 \%$ in 2020, reflecting not only the evolution of oil-product trade but also the loss of competitiveness of energy-intensive industries based in oil-exporting countries, as explained below. This trade reduction in oil-exporting countries is partly compensated by a reallocation of their exports of oil products towards OECD countries (with an increase of around 3\% in 2020). Meanwhile, other bilateral trade adjustments - when expressed in terms relative to the baseline - remain marginal.

While relatively important in terms of their magnitude, adjustments in fossil-fuel trade flows remain restricted to relatively small segments of international trade. A major source of trade reallocation concerns trade in the products of energy-intensive industries (EIIs). Because a removal of fossil-fuel subsidies increases the price of intermediates for the EIIs of oil-exporting countries, and since the energy prices faced by OECD countries are now lower, the EIIs in OECD countries record competitiveness gains at the expense of EIIs in oil-exporting countries. Indeed, the export surplus recorded by OECD countries (of around USD 30 billion in 2020) results primarily from additional exports of EII products (for an amount of USD 48 billion). Thus, while OECD countries gain market 
shares in exports of EIIs, they also import more crude oil and refined oil products from oil-exporting countries for as much as USD 13 billion. This accounts for almost half of the total increase in imports by OECD countries (USD 30 billion in 2020). This reallocation of EII trade is also a major driver of the adjustment faced by oil-exporting countries who experience a drop in their EII exports of USD 32 billion (20\% of their baseline levels) in 2020. At the same time, imports of EII products by oil-exporting countries increase by USD 25 billion (11\% of their baseline levels), highlighting the loss of competiveness of domestic EIIs in oil-exporting countries.

\section{Figure 3. Trade reallocation across regional trading area from} a multilateral removal of fossil-fuel subsidies

(\% deviations in 2020 relative to the baseline)

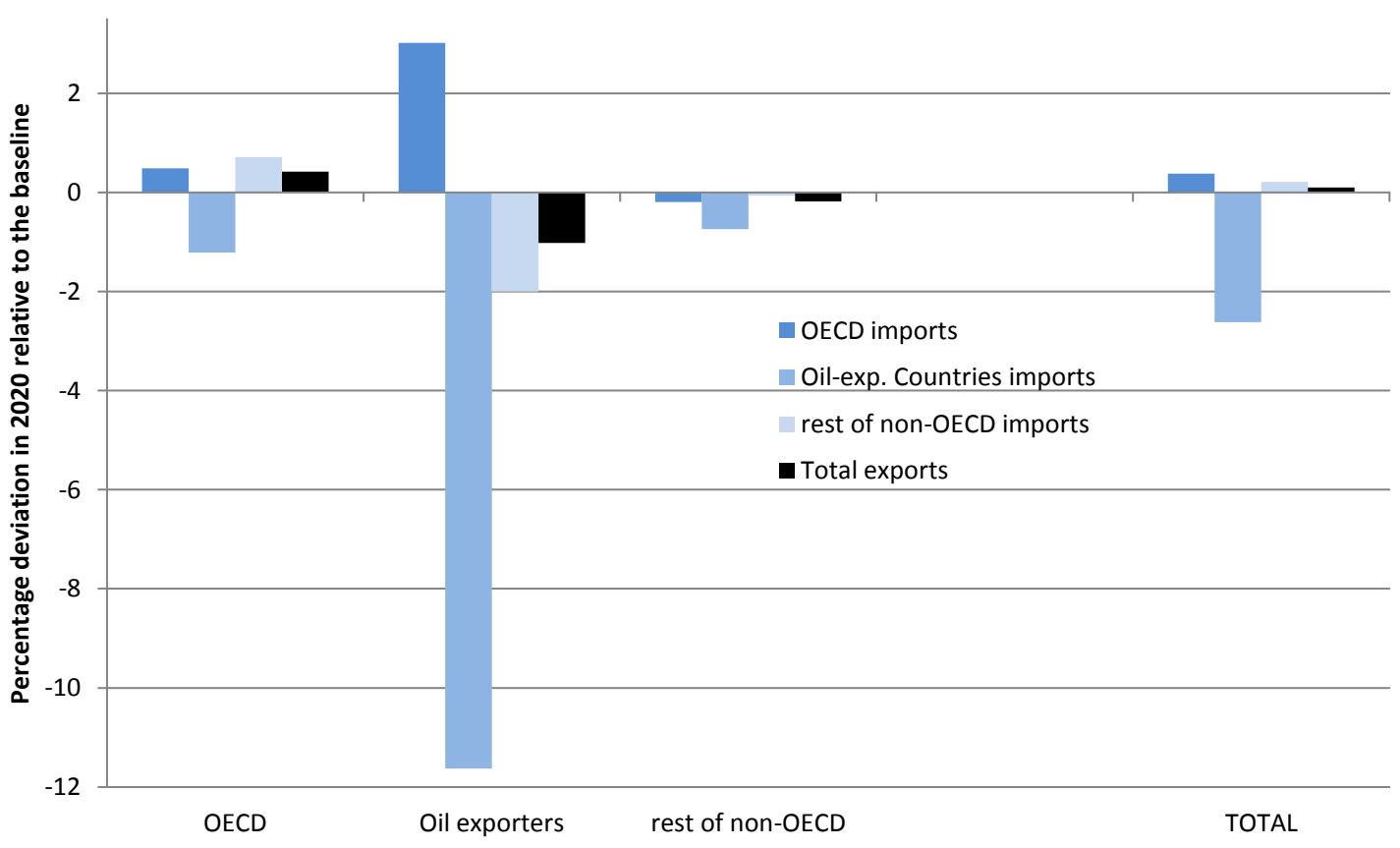

Bars correspond to bilateral trade flows. For instance, the four bars corresponding to "oil exporters" show the percentage change in the volume of trade relative to the baseline of imports from OECD countries $(+3 \%)$, imports from oil-exporting countries (-11.5\%), imports from the rest of the world (-2\%), and total exports ($1 \%)$.

Source: OECD ENV-Linkages Model based on fossil-fuel subsidies data estimated by the IEA.

The removal of fossil-fuel subsidies in oil-exporting countries and the resulting decline in international oil prices thus induce a reallocation of EIIs trade in favour of OECD countries. Rather surprisingly, this occurs despite the existence of caps on OECD countries' GHG emissions, consistent with the assumption that these countries restrict their emissions to the targets they announced after COP15. The explanation relates to the way the emissions cap is implemented in OECD countries. Total GHG emissions in OECD countries are capped to their baseline levels - so as to prevent leakage - but the model applies the caps globally at the total OECD level and includes all gases, thereby allowing for the trading of emissions across member countries and gases. Therefore, the cap implies a low carbon price, common to all OECD countries and gases, which, as far as $\mathrm{CO}_{2}$ is concerned, is largely offset by the fall in international fossil-fuel prices resulting from subsidy reform. This allows $\mathrm{CO}_{2}$ emissions to increase above their baseline 
levels and EIIs to expand, reflecting the shift in international competitiveness and the corresponding trade reallocation. As a result, the OECD cap is met by reducing non- $\mathrm{CO}_{2}$ emissions, sometimes substantially as in the cases of the European Union $(-26 \%)$ and Japan $(-23 \%)$.

\section{Long-term effects}

While subsidy reform is modelled as being completed in 2020, its long-term effects appear important too, reflecting the adjustment dynamics embodied in the model. ${ }^{11}$ World GHG emissions fall even further, from $3 \%$ in 2020 to $10 \%$ in 2050 . International prices for oil and gas also keep falling beyond 2020, although at a slower pace for oil, due to the delayed adjustment of the industrial structure in those countries that have removed their subsidies after 2020. The one-off real income gain reported in oil-exporting countries that have removed subsidies is gradually offset by the adverse longer-term impact on their economic growth of the subsidy removal, which increases the cost of investment and reduces the rate of capital accumulation in these countries. As a result, the contribution of oil-exporting countries to total world trade volumes keeps shrinking beyond 2020. As Figure 4 illustrates, exports from oil-exporting countries in 2050 would be more than $6 \%$ below their baseline level (1\% below the baseline level in 2020). This in part reflects the fact that exports to OECD countries would fall by $4 \%$ relative to the baseline (instead of increasing as in 2020), reflecting mainly the loss of competitiveness of oil-exporting countries' energy-intensive industries on the international markets. Meanwhile, total import volumes of oil-exporting countries would fall by almost $4 \%$ in 2050 (compared with around $2 \%$ in 2020) as a result of a $2 \%$ fall relative to the baseline of OECD exports to oil-exporting countries (compared with a $1 \%$ reduction in 2020).

In summary, the adverse impact of subsidy reform on long-term growth in oilexporting countries implies a further reduction in trade from and to oil-exporting countries beyond 2020. That reduction is no longer offset by a corresponding increase in trade volumes from and to OECD countries - first, because the international price of oil keeps falling after 2020 but at a slower pace than during the period when subsidies were removed; second, because the expansion of OECD exports beyond 2020, in particular for goods of energy-intensive industries, is hindered in the long term by the reduction of import demand by oil-exporting countries. Despite these restrictions, the share of OECD countries in world trade increases relative to the baseline in 2050, although to a relatively small extent (Figure 4): total OECD export volumes increase by $0.6 \%$ (an increase of USD 122 billion, of which 90\% correspond to energy-intensive goods) and total OECD import volumes increase by $0.3 \%$ (an increase of USD 53 billion, entirely accounted for by additional imports of fossil fuels). ${ }^{12}$

11. In particular, due to the existence of two different capital vintages with a "putty clay" production structure for each sector. This particular production structure assumes that the elasticity of substitution among factors is lower for old capital than for new. This implies a longer adjustment of quantities to price changes.

12. The compositional change of OECD imports from oil-exporting countries in 2050 is therefore characterized by an increase in fossil-fuel import volumes that is more than compensated by a rather sharp drop by more of $20 \%$ of imports of energy-intensive commodities originating from these countries. 


\section{Impact on greenhouse-gas emissions under the central scenario}

The ENV-Linkages model takes into account both $\mathrm{CO}_{2}$ and non- $\mathrm{CO}_{2}$ greenhouse gases since the latter are also a significant contributor to climate change. While $\mathrm{CO}_{2}$ emissions are directly attributed to the combustion of fossil fuels and the flaring of natural gas, non- $\mathrm{CO}_{2} \mathrm{GHG}$ emissions (i.e. methane, nitrous oxide and industrial gases such as sulfur hexafluoride) are either associated with other activities like livestock production or the chemicals industry - and are therefore only indirectly affected by energy prices - or with energy production. Coal mining and natural-gas transportation are activities that emit significant quantities of methane, for example.

These features of the model allow a further assessment of the environmental impact of subsidy reform over the medium and longer term. Under the central scenario of a multilateral subsidy removal over the 2013-20 period, global GHG emissions would fall by about $10 \%$ in 2050 relative to the baseline. While this percentage may seem at first modest, the underlying breakdown by geographical area reveals a wide disparity among the countries covered. Oil-exporting countries are the most affected, with a total drop of about $37 \%$ in total GHG emissions, as is Russia with a decrease approaching $23 \%$. India and China also experience a decrease in all types of GHG emissions, although on a smaller scale (-15\% and $-7 \%$ respectively). By contrast, carbon leakage would result in a small increase for EU and EFTA countries taken as a whole. It should, however, be noted that these estimates do not take into account the effect of removing measures that support consumption of fossil fuels in OECD countries. Figure 5 illustrates the detailed breakdown by geographical area.

Figure 4. Trade reallocation across regional trading area from a multilateral removal of fossil-fuel subsidies

(\% deviations in 2050 relative to the baseline)

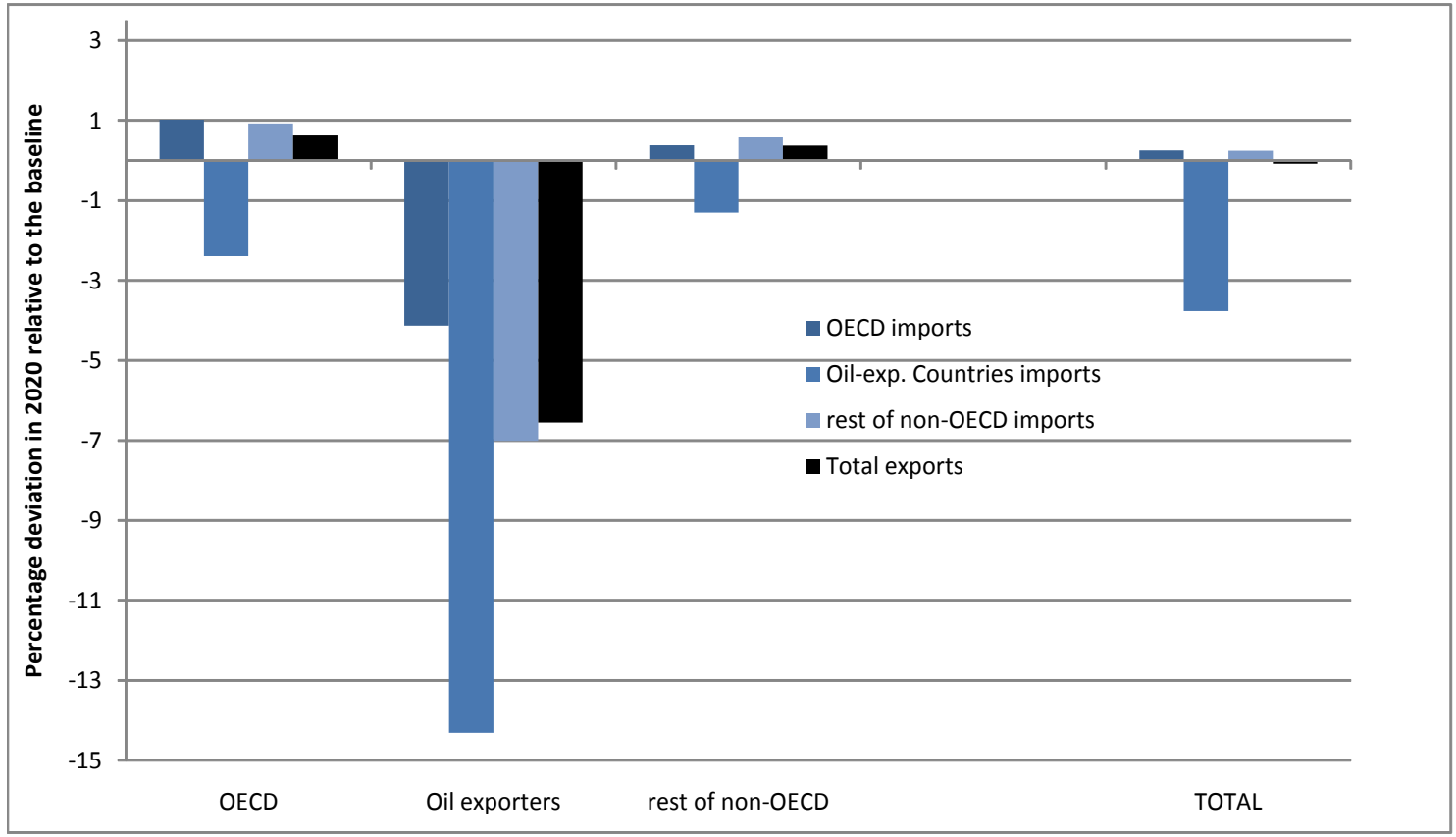

Source: OECD ENV-Linkages model based on fossil fuel subsidies data for 2008 estimated by the IEA (2010). 
Figure 5. Central scenario: The impact on GHG emissions at the 2050 horizon

(\% deviations in 2050 relative to the baseline)

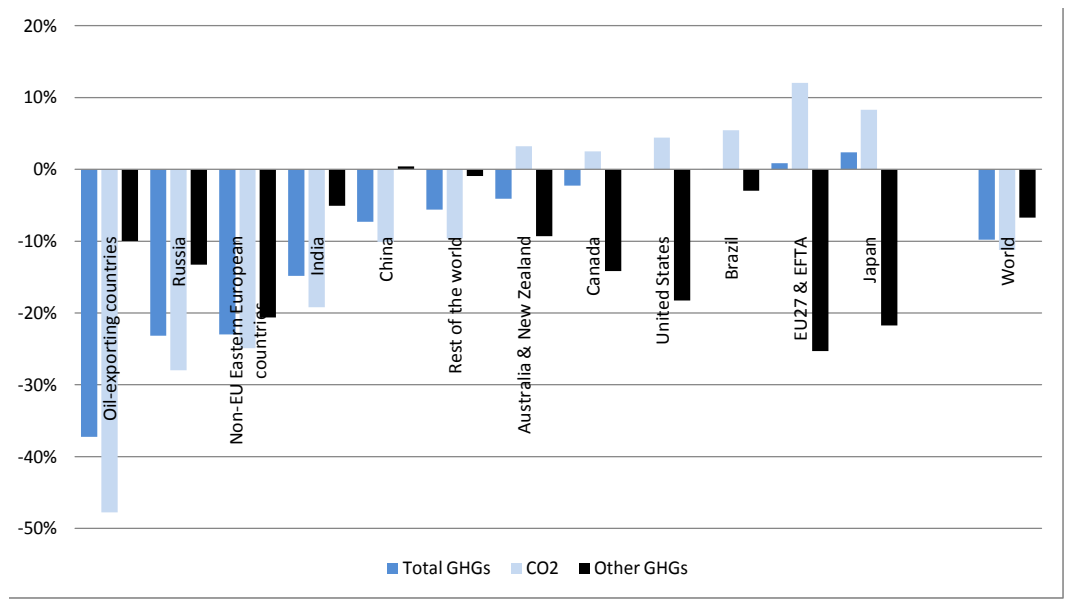

Source: OECD ENV-Linkages Model based on fossil-fuel subsidies data estimated by the IEA.

\section{Concluding remarks}

Removing subsidies to the consumption of fossil fuels features as a priority option in the portfolio of policies aimed at stabilising the concentration of GHGs in the atmosphere. Although reforming such subsidies would not alone be sufficient to meet this goal, it would both help reduce GHG emissions while bringing real income gains to some of the countries that undertake the reforms. As a complement to previous OECD analysis (IEA, OPEC, OECD, World Bank, 2010; Burniaux and Chateau, 2011), this paper analyses the trade impacts of such a scenario of subsidy removal.

Simulation using the OECD ENV-Linkages CGE model shows that the removal of fossil-fuel subsidies in non-OECD countries would have almost no impact on total trade volumes at a global level while generating compositional changes both across traded goods and services, and trading areas. Trade in fossil fuels, especially coal and natural gas, would be reduced although these fuels account for a relatively small segment of total world trade. This reduction would be further compensated, at least in the medium term, by an expansion of trade in energy-intensive goods. As for the effects among different trading areas, reforming fossil-fuel subsidies would increase the contribution of OECD countries to total world trade at the expense of a reduction in oil-exporting countries' imports and exports. This evolution stems from both a loss of competitiveness incurred by producers of energy-intensive goods in oil-exporting countries that remove their subsidies, and - at least in the medium term - by a corresponding gain in the competitiveness reported by energy-intensive industries in OECD countries (due to the fall of international fossil-fuel prices). 


\section{References}

Burniaux, J.-M., J.P. Martin and J. Oliveira-Martins (1992), "The effects of existing distortions in energy markets and the costs of policies to reduce $\mathrm{CO}_{2}$ emissions: Evidence from GREEN", OECD Economic Studies, 19 (Winter), OECD Publishing.

Burniaux, J.-M., J. Chateau, J. Dellink, R. Duval and S. Jamet (2009), "The Economics of Climate Change Mitigation: How to Build the Necessary Global Action in a Cost-effective Manner", OECD Economics Department Working Papers, No. 701, OECD Publishing.

Burniaux, J.-M. and J. Chateau (2010), An Overview of the OECD ENV-Linkages Model, background report to the joint report by IEA, OPEC, OECD, and The World Bank on "Analysis of the Scope of Energy Subsidies and Suggestions for the G-20 Initiative", May.

Burniaux, J.M. and J. Chateau (2011), "Mitigation Potential of Removing Fossil Fuel Subsidies: A General Equilibrium Assessment", OECD Economics Department Working Papers, No. 853, OECD Publishing.

Coady, D., R. Gillingham, R. Ossowski, J. Piotrowski, S. Tareq and J. Tyson ( 2010), Petroleum Product Subsidies: Costly, Inequitable, and Rising, IMF Staff Position Note No. SPN/10/05, 25 February, International Monetary Fund, Washington, D.C.

Duval, R. and C. de la Maisonneuve (2010), "Long-run growth scenarios for the world economy", Journal of Policy Modeling, Vol. 32, No. 1, January-February.

Ianchovichina, E. and R. McDougall (2000), Theoretical Structure of Dynamic GTAP, GTAP Technical Paper No. 17, December.

IEA (1999), World Energy Outlook 1999, International Energy Agency, Paris.

IEA (2006), World Energy Outlook 2006, International Energy Agency, Paris.

IEA (2008), World Energy Outlook 2008, International Energy Agency, Paris.

IEA, OPEC, OECD, World Bank (2010), "Analysis of the Scope of Energy Subsidies and Suggestions for the G-20 Initiative", Joint Report prepared for submission to the G-20 Meeting of the Finance Ministers and Central Bank Governors on 5 June 2010, Busan (Korea), 26 May.

Koplow, D. (2009), Measuring energy subsidies using the price gap approach: what does it leave out?, Global Subsidies Initiative of the International Institute for Sustainable Development, Geneva: www.iisd.org/pdf/2009/bali_2_copenhagen_ff_subsidies_pricegap.pdf.

McKibbin, W.J. and P.J. Wilcoxen (1999), "The theoretical and empirical structure of the GCubed model", Economic Modelling, Vol. 16, No. 1, January.

OECD (2003), Environmentally Harmful Subsidies: Policy Issues and Challenges, OECD, Paris.

OECD (2009), The Economics of Climate Change Mitigation: Policies and Options for Global Action Beyond 2012, OECD, Paris. 